\title{
A construção social da qualidade da farinha de mandioca em comunidades rurais na Amazônia paraense
}

\section{Social construction of the quality of cassava flour in rural communities in paraenese amazon}

Fagner Freires de Sousa - Mestrando no Programa de Pós-Graduação em Agriculturas Amazônicas, Núcleo de Ciências Agrárias e Desenvolvimento Rural/NCADR da UFPA. E-mail: sousa.ffreires@gmail.com

Marc Piraux - Doutor, pesquisador do CIRAD Montpellier e professor visitante do Núcleo de Ciências Agrárias e Desenvolvimento Rural/NCADR da UFPA. E-mail: marcpiraux@uol.com.br

\section{Resumo}

A farinha de mandioca é um produto agrícola muito apreciado no Pará e tem sua qualidade definida poruma diversidade de representações e práticas de agricultores, comerciantes e consumidores. Essa pesquisa buscou entender quais são as concepções de qualidade dos agricultores e comerciantes e como estas influenciam nas práticas de produção e na qualidade da farinha em duas comunidades distintas na Amazônia paraense. A partir de entrevistas e classificação da farinha, constatou-se que nas duas comunidades a qualidade da farinha é uma construção social, a qualse inicia na plantação da roça, perpassando por todo processo tecnológico, com destaque para o saber fazer, às práticas de higiene e à relação agricultor-comerciante, desconsiderando-se os padrões de qualidade das agências reguladoras.

\section{Palavras-chave}

Agricultura familiar; relações sociais; produção tradicional; agroindustrialização; saber fazer.

\begin{abstract}
The cassava flour is an agricultural product very appreciated in Pará and its quality is defined by a variety of representations and practices of farmers, merchants and consumers. This research sought to understand the conceptions of quality of farmers and merchants and how they influence the practices of production and quality of the flour in two distinct communities in paraense Amazon. From interviews with farmers and merchants and classification of flour, it was found that in both communities the flour's quality is a social construction, which starts in planting, passing by every technological process, highlighting the know-how, at hygiene practices and farmer-merchant relationship, disregardingquality's standards of regulatory agencies.
\end{abstract}

\section{Keywords}

Family agriculture; social relations; traditional production; agroindustrialization; know-how. 


\section{INTRODUÇÃO}

A qualidade dos alimentos nos moldes do atual modelo globalizado é baseada principalmente em parâmetros normativos, referentes às condições físicas e higiênico-sanitárias (TRICHES, 2012). No entanto, nos últimos anos, o consumo mundial de alimentos passou a ser orientado por diversas percepções de qualidade em virtude do desenvolvimento e crescimento do mercado agroalimentar (ESTIVAL, 2013).

Dentre estas percepções, há tendências emergentes que estão atreladas aos saberes tradicionais e às relações sociais locais (TRICHES, 2012), as quais se relacionam, sobretudo, à produção de alimentos tradicionais - os produtos da terra - que segundo Cruz (2009), são alimentos "produzidos localmente, a partir de procedimentos avaliados (pelos consumidores) como ambiental, social e economicamente sustentáveis, enraizados em um território e em uma cultura".

No entanto, os alimentos produzidos de forma tradicional no Brasil, continuam sofrendo repressão de órgãos fiscalizadores, uma vez que as normas de qualidade são associadas aos modelos baseados na produção em larga escala e garantia de sanidade, o que está além da capacidade de produção da agricultura familiar, pois os agricultores se utilizam de outros parâmetros que são diferentes dos padrões hegemônicos, ficando à margem dos canais formais de produção e comercialização de alimentos (CRUZ, 2009).

Sonnino e Marsden (2006), no entanto, consideram que a qualidade envolve um processo social de qualificação, o qual requer a construção e negociação entre os atores envolvidos. Prigent-Simonin e Hérault-Fournier (2005), por sua vez,acrescentam que as relações diretas entre produtores e consumidores modificam a percepção de qualidade, e ela própria pode ser caracterizada como uma dimensão de qualidade.

Segundo Wilkinson,a qualidade apresenta noções variadas, as quais estão em concorrência e contestação, revelando valores distintos por trás das normas e técnicas. Para este autor,"o que para alguns são valores estéticos associados à produção artesanal, para outros são indicadores de ameaça à saúde pública. $\mathrm{O}$ que para alguns são os valores de eficiência, para outros são premissas na geração de externalidades inadmissíveis" (WILKINSON, 2002, p.818).

Essas considerações valem para a farinha de mandioca, que na Amazônia paraense, e mais especificamente em comunidades rurais do Território do Baixo Tocantins ${ }^{1}$, constitui a base alimentar da população. A farinha nas comunidades rurais paraenses apresenta formas de produção diversas baseadas na tradição e

\footnotetext{
Utilizou-se a classificação dos Territórios da Cidadania, sendo o Território do Baixo Tocantinscomposto por 11 municípios: Abaetetuba, Acará, Baião, Barcarena, Cametá, IgarapéMiri, Limoeiro do Ajuru, Mocajuba, Moju, Oeiras do Pará e Tailândia.
} 
cultura de cada agricultor, os quais traduzem através do fazer farinha seus saberes e seus modos de vida (SILVA, 2011).

Assim, este trabalho dedica-se a investigar o que os agricultores entendem por qualidade da farinha e como as relações entre eles e comerciantes/consumidores²influenciam nas práticas de produção adotadas, e consequentemente, na qualidade físico-química e higiênico-sanitária da farinha produzida. Três hipóteses estruturam a essa reflexão. A primeira é que a qualidade da farinha é construída socialmente de acordo com percepções diversas dos atores sociais envolvidos na cadeia de produção; a segundaé que esta percepção orienta as práticas adotadas por cada um dos agricultores no fazer farinha, e por fim, a terceira é que tal percepção contrasta com a percepção de agentes externos envolvidos no processo de qualificação da farinha, tais como os comerciantes e as agências de normatização que regulamentam a produção e qualificação da farinha como alimento.

O artigo esta dividido em cincotópicos principais: o primeirotrata da metodologia utilizada para o desenvolvimento da pesquisa; no segundo são apresentadas as comunidades, campo dessa pesquisa, e as distinções no fazer farinha praticada pelos agricultores destas comunidades; no terceiro são apresentados os elementos da interação social que orientam à construção social da qualidade da farinha; no quarto apresenta-se a qualidade da farinha segundo os padrões normativos; e, no quinto e último, são apresentadas as conclusões possibilitadas pela pesquisa.

\section{METODOLOGIA}

A investigação foi realizada a partir de duas comunidadespertencentes ao Território do Baixo Tocantins: Baratinha, localizada no município de Mocajuba e Nova Paz, no município de Tailândia. As comunidades foram escolhidas por figurarem no cenário local como 'produtoras de farinha de qualidade' e por apresentarem distintas práticas de manejo da mandioca e produção da farinha, sendo empregada a prática tradicional de produção em Baratinha e a agroindustrial em Nova Paz.

A pesquisa apoiou-se em métodos das ciências sociais e ciências naturais, a fim de compreender e apreender as diversas dimensões que a qualidade da farinha pode apresentar, segundo descrito a baixo.

\footnotetext{
2 Nesta pesquisa não foram realizadas entrevistas com consumidores, no entanto, entende-se que as exigências dos comerciantes sofrem influência direta das preferências dos consumidores.
} 


\subsection{ANÁLISE DA PERCEPÇÃO DE QUALIDADE DOS AGRICULTORES}

Os métodos de pesquisa utilizados basearam-se, inicialmente na realização de diagnósticos rurais participativos (VERDEJO, 2006) nas duas comunidades (COSTA et al., 2014; LINHARES et al., 2014), os quais oportunizaram conhecer os sistemas de produção locais,e assim, compreender o processo de produção e comercialização da farinha e identificar os atores envolvidos nas diferentes etapas desta cadeia produtiva em cada comunidade.

Identificado esses atores, foram aplicados questionários semiestruturados e realizadas entrevistas abertaspara 10 agricultores de cada comunidade, para 4 e 6 comerciantes, respectivamente, nos mercados de farinha de Tailândia e Mocajuba e 3 atravessadores em Areião ${ }^{3}$, Cametá. A amostragem compreendeu 33,3\% do universo de produtores de farinha em Nova Paz e Baratinha; 66\% e 75\%, dos comerciantes encontrados nos mercados de Tailândia e Mocajuba nos dias de pesquisa,respectivamente; e 100\% dos atravessadores encontrados em Areião. Os agricultores foram selecionados, considerando a diversidade de práticas de manejo da mandioca e produção da farinha, de acordo com os resultados dos diagnósticos (COSTA et al., 2014; LINHARES et al., 2014), enquanto os comerciantes foram selecionados de acordo com a disponibilidade e interesse em participar.

As perguntas do questionário e das entrevistas versavam sobre o entendimento que agricultores, comerciantes e atravessadores de farinha tinham sobre qualidade, assim como dos fatores do processo de produção da farinha (do cultivo à comercialização) que poderiam influenciar negativa ou positivamente a construção dessa qualidade por eles definida. Assim, indagou-se sobre as práticas de manejo da mandioca, sobre o beneficiamento da mandioca para fabricação da farinha, sobre higiene e sobre as características sensoriais da farinha dita "de qualidade". Além disso,indagou-se sobre a relação da qualidade com a formação do preço da farinha nos mercados locais.

A aplicação dos questionários aos agricultores foi realizada em suas residências ou nas próprias casas de farinha, em seguida, as entrevistas foram negociadas e realizadas posteriormente, utilizando-se de gravador de voz, mediante autorização dos mesmos (BEUAD; WEBER, 2007). Já com os comerciantes e atravessadores, as entrevistas foram realizadas nos mercados de farinha de Mocajuba e Tailândia e no Porto de Areião, também utilizandoo gravador de voz, quando autorizado.

Além disso, a fim de complementar as informações e melhor compreender o discurso desses indivíduos, também foi utilizada a técnica de observação

3 Importante ponto de escoamento da farinha produzida em Baratinha. 
participante (BEAUD; WEBER, 2007) durante a produção de farinha de alguns agricultores nas duas comunidades, e durante a comercialização da farinha produzida por esses mesmos agricultores, nos respectivos pontos de escoamento.

\subsection{CLASSIFICAÇÃO DAS FARINHAS PRODUZIDAS NAS COMUNIDADES}

Foram coletadas 3 amostras de $1 \mathrm{~kg}$ das farinhas produzidas nas comunidades, as quais foram submetidas à classificação,segundo a Instrução Normativa $n^{\circ} 52$, de 7 de novembro de 2011 (BRASIL, 2011). A classificação deu-se em grupos (seca ou d'água), segundo o processo tecnológico utilizado na produção e em classe (fina, média ou grossa), segundo a granulometria.A classificação em tipos não foi possível em virtude da impossibilidade de realização de algumas análises (teor de amido e teor de fibras brutas), no entanto, foram realizadas análises de contaminantes físicos, presença de mofos perceptível a olho nu e análise sensorial, os quais possibilitam a verificação de conformidade do produto.

A análise granulométrica foi realizada no Laboratório de Agroindústria da Embrapa Amazônia Oriental e foi realizada através de um conjunto de peneiras com abertura de malha de $1 \mathrm{~mm}$ e $2 \mathrm{~mm}$ e um fundo, sob agitação manual. A mesma foi realizada em triplicata.

Além disso, foram realizadas análises físico-químicas de acidez, pelo método de titulação aquossolúvel (AOAC, 1997), umidade e cinzas, segundo metodologias do Instituto Adolfo Lutz (2008), para verificação de conformidade quanto ao conteúdo químico das farinhas (BRASIL, 2011). Todas as análises foram realizadas em triplicata no Laboratório de Tecnologia de Alimentos da Universidade do Estado do Pará. Os resultados foram submetidos à análise de variância ANOVA e comparação das médias pelo teste de Tukey $(\mathrm{p} \leq 0,05)$.

\section{A DIVERSIDADE DA PRODUÇÃO DA FARINHA NAS COMUNIDADES}

Aqui apresenta-se as comunidades onde a pesquisa foi realizada e, posteriormente, as particularidades de cada uma quanto ao fazer farinha.

\subsection{AS DISTINTAS COMUNIDADES}

Nova Paz, em Tailândia e Baratinha, em Mocajuba, são comunidades que apresentam o cultivo de mandioca, produção e comercialização de farinha como atividades em comum, no entanto, com dinâmicas de produção distintas. 
Baratinha localiza-se na região central do município de Mocajuba, distante a $10 \mathrm{~km}$ da PA - 151, situa-se no entorno de uma vicinal. Apresenta relação bem próxima com a sede do município e com a Vila de Areião, Cametá, devido questões históricas e ao mercado de farinha. É composta por aproximadamente 37 famílias, em sua quase totalidade originária do próprio município de Mocajuba e municípios adjacentes, que apresentam em comum o cultivo da mandioca, o qual ao longo da história predomina como a principal atividade econômica dos agricultores da comunidade (LINHARES et al., 2013).

A comunidade Nova Paz, localiza-se na zona rural do município de Tailândia, situada no entorno de uma vicinal ligada à PA-150 e distante $22 \mathrm{~km}$ da sede municipal. Sua formação data-se da década de 1970, em virtude da intensificação da exploração madeireira na região, a qual foi responsável pela construção da vicinal e fixação dos primeiros moradores. Atualmente a comunidade é constituída por cerca de 100 famílias, as quais são oriundas principalmente do estado do Maranhão e municípios do nordeste paraense, que foram atraídos pelo comércio madeireiro e pela facilidade de acesso às terras não desmatadas na época de formação. A exploração madeireira era a principal atividade econômica nos anos iniciais da comunidade, no entanto, a partir do esgotamento dos recursos naturais e aumento da fiscalização ambiental a partir das Operações Arco de Fogo e Arco Verde a agricultura passou a apresentar destaque. Hoje, 83\% das familias ${ }^{6}$ praticam a agricultura e 63\% destas cultivam mandioca para produção de farinha, com área plantada média de 4,2 ha (COSTA et al., 2013).

\subsection{A DISTINSÃO DA PRODUÇÃO DA FARINHA NAS COMUNIDADES}

A produção da farinha na comunidade Baratinha é marcada por um processo de mudanças. No período de fundação da comunidade predominava a produção de farinha d'agua ${ }^{7}$, a qual era considerada sem qualidade pelos compradores, percepção hoje compartilhada pelos agricultores da comunidade, pois consideram que a farinha d'água era visualmente feia, devido à coloração roxa e ao sabor amargo que apresentava. A percepção da necessidade de mudança no processo produtivo veio em decorrência da dificuldade de comercialização da

4 Ação conjunta do Ibama, Polícia Federal, Força Nacional de Segurança e Governo do Estado do Pará contra o desmatamento ilegal da Amazônia.

5 A Operação Arco Verde foi idealizada a pedido do Presidente da República em decorrência da repercussão das ações implementadas pela Operação Arco de Fogo, principalmente no município de Tailândia - Pará, no início do mês de março de 2008. Mais informações: http:// www.mma.gov.br/estruturas/178/_ECAP/178_ecap17122009052752.pdf.

6 Universo de 45 famílias entrevistadas durante o diagnóstico (COSTA et al., 2013).

7 Farinha produzida exclusivamente a partir de massa de mandioca fermentada. 
farinha e seguiu uma série de experimentação e troca de informação por parte dos agricultores de Baratinha e comunidade circunvizinhas, assim como a inserção de novas tecnologias na casa de farinha.

A produção atual é principalmente de farinha mista ${ }^{8}$, resultado de um tipo de beneficiamento que foi aprimorado a partir da inserção de novas ferramentas (como o caititu'), condicionando adaptações e/ou mudanças de práticas (NUNES; SIMÕES, 2014). Tais mudanças são decorrentes das experimentações e conhecimentos dos próprios agricultores, os quais ao longo dos anos não receberam assistência técnica voltada para esta atividade. Dessa forma, atualmente a fabricação da farinha na comunidade Baratinha é realizada exclusivamente de forma tradicional, com forte presença de instrumentos como o tipiti ${ }^{10}$, a peneira e o rodo.

Contrastando, em Nova Paz, a produção de farinha segue um processo de especialização, resultante da constante assistência técnica de órgãos como EMATER, Embrapa e Secretária Municipal de Agricultura, e aquisição de crédito agrícola do programa Desenvolvimento Regional Sustentável, voltado para a cultura da mandioca, o que possibilitou, em 2009, a implantação de uma agroindústria comunitária, com estrutura para produção de 1,2 ton. de farinha diariamente, fortalecendo a dinâmica de produção dos agricultores. Dessa forma, a produção nas tradicionais casas de farinha tem sido crescentemente substituída pela produção agroindustrial, caracterizada pelos agricultores locais como mais produtiva e menos penosa, em virtude da mecanização do processo, o qual passa a contar com trituradores, prensa hidráulica e fornos com mexedores mecânicos, além de apresentar estrutura muito diferente dos tradicionais retiros, com paredes em alvenaria rebocada lisa, piso cimentado, teto etc.. No entanto, com isso, tem sido recorrente a necessidade de contratação de mão de obra, principalmente para as etapas de descasque e prensagem, em virtude do aumento de produtividade resultante da mecanização.

8 Segundo a Portaria n ${ }^{\circ}$ 554, de 30 de agosto de 1995 , entendia-se por farinha mista“o produto obtido mediante a mistura, antes da prensagem, da massa de mandioca ralada com a massa de mandioca fermentada, na proporção de 75 a $80 \%$ da primeira massa e 20 a 25\% da segunda, de acordo com a preferência do mercado consumidor, seguindo após a mistura das massas, o processo tecnológico da farinha de mandioca d'água" e é assim considerada pelos agricultores, levando-nosa optar por utilizá-la, no entanto, ressalta-se que essa Portaria foi substituída pela Instrução Normativa no 52, de 7 de novembro de 2011, a qual nãoapresenta o grupo "farinha mista", enquadrando-a como farinha d'água.

9 Equipamento com um cilindro com pequenos dentes para ralar a mandioca, movido à eletricidade ou a diesel.

10 Tipo de cesto comprido, trançado em fibras vegetais, usado para espremer, ao ser fortemente esticado, a massa de mandioca para retirada da manipueira e redução da umidade da massa. 
Assim, em Nova Paz, predomina a produção de farinha seca, o que é demandado pelo processo de fabricação empregado, uma vez que a agroindústria é comunitária e funciona por escala ${ }^{11}$, sendo possível a utilização da mesma por no máximo dois dias pela mesma família, inviabilizando a produção de farinha d'água ou mista em virtude do tempo necessário para fermentação das raízes. No entanto, alguns agricultores ainda mantém o retiro tradicional, no qual se produz farinha d'água e/ou mista, principalmente para o consumo da família.

Embora as comunidades apresentem dinâmicas de produção distintas, as etapas de produção da farinha são basicamente as mesmas, com particularidades apenas quanto as tecnologias e os instrumentos utilizados e, em alguns casos, quanto a mão-de-obra utilizada e a divisão do trabalho por gênero, como pode ser observado no Quadro 1.

Quadro 1 - Especificidades nas etapas de produção da farinha nas distintas comunidades

\begin{tabular}{|l|l|l|}
\hline Etapas & Baratinha & Nova Paz \\
\hline Colheita & $\begin{array}{l}\text { Colheita manual; mão-de-obra familiar e contratada; trabalho feminino e } \\
\text { infantil. }\end{array}$ \\
\hline $\begin{array}{l}\text { Transporte das } \\
\text { raízes }\end{array}$ & $\begin{array}{l}\text { Carroças tracionadas por bois ou em ca- } \\
\text { çoás. }\end{array}$ & Tratores contratados. \\
\hline $\begin{array}{l}\text { Limpeza das raí- } \\
\text { zes }\end{array}$ & $\begin{array}{l}\text { Lavagem grosseira em bacias ou tambo- } \\
\text { res. }\end{array}$ & - \\
\hline Descasque & $\begin{array}{l}\text { Descasque manual com descascador ela- } \\
\text { borado pelos agricultores da comunida- } \\
\text { de; mão-de-obra familiar. }\end{array}$ & $\begin{array}{l}\text { Descasque manual com facas; } \\
\text { mão-de-obra contratada e fa- } \\
\text { miliar. }\end{array}$ \\
\hline $\begin{array}{l}\text { Lavagem } \\
\text { Fermentação }\end{array}$ & $\begin{array}{l}\text { Lavagem mais criteriosa com imersão } \\
\text { das raízes em bacias ou no igarapé; tra- } \\
\text { balho feminino. }\end{array}$ & $\begin{array}{l}\text { Lavagem a partir da imersão e } \\
\text { revolvimento das raízes em tan- } \\
\text { ques d'água para este fim; traba- } \\
\text { lho masculino. }\end{array}$ \\
\hline $\begin{array}{l}\text { Desintegração das raízes com cascas, armaze- } \\
\text { cián ou no igarapé por cerca de 3 dias. }\end{array}$ & $\begin{array}{l}\text { Uso do caititu a diesel ou elétrico para } \\
\text { raízes fralagem frescas e uso do soquete para raí- } \\
\text { ou socagem) }\end{array}$ & $\begin{array}{l}\text { Uso do caititu elétrico. } \\
\text { zes fermentadas. }\end{array}$ \\
\hline $\begin{array}{l}\text { Mistura e bolea- } \\
\text { mento }\end{array}$ & $\begin{array}{l}\text { Mistura da massa de mandioca ralada e } \\
\text { fermentada e formação de bolas para } \\
\text { prensagem. }\end{array}$ & \begin{tabular}{l} 
- \\
\hline Prensagem \\
ou infantil.
\end{tabular} \\
\hline
\end{tabular}

11 O funcionamento da agroindústria é baseado em agendamento, onde se estabelece uma escala de utilização pelos agricultores. 


\begin{tabular}{|c|c|c|}
\hline $\begin{array}{l}\text { Desintegração da } \\
\text { massa }\end{array}$ & $\begin{array}{l}\text { Utilização de peneiras artesanais; traba- } \\
\text { lho feminino e/ou infantil. }\end{array}$ & $\begin{array}{l}\text { Utilização de moinhos elétricos } \\
\text { com peneiras graduadas; traba- } \\
\text { lho masculino. }\end{array}$ \\
\hline $\begin{array}{l}\text { Escaldamento e } \\
\text { torração }\end{array}$ & $\begin{array}{l}\text { Utilização de fornos de chapa de cobre } \\
\text { ou ferro e rodo de madeira para revolvi- } \\
\text { mento da massa pelo torrador. }\end{array}$ & $\begin{array}{l}\text { Utilização de fornos metálicos } \\
\text { de forma circular, os quais apre- } \\
\text { sentam palhetas mecânicas para } \\
\text { o revolvimento da massa. }\end{array}$ \\
\hline Classificação & $\begin{array}{l}\text { Utilização de telas metálicas com gradua- } \\
\text { ção granulométricas e agitação manual. }\end{array}$ & $\begin{array}{l}\text { Utilização de trituradores com } \\
\text { peneiras graduadas, sob agita- } \\
\text { ção mecânica. }\end{array}$ \\
\hline Esfriamento & \multicolumn{2}{|c|}{ Disposição da farinha em cochos de madeira em temperatura ambiente. } \\
\hline Embalagem & $\begin{array}{l}\text { Embalados em sacos de polietileno de } \\
30 \mathrm{~kg} \text {, recobertos com sacos de serapi- } \\
\text { lheira; a medida é realizada com auxilio } \\
\text { de litros ( } 24 \text { litros). }\end{array}$ & $\begin{array}{l}\text { Embalada em sacos de polieti- } \\
\text { leno de } 60 \mathrm{~kg} \text {, recobertos com } \\
\text { sacos de serapilheira; a medida } \\
\text { é realizada com o auxilio de ba- } \\
\text { lanças. }\end{array}$ \\
\hline
\end{tabular}

Fonte: Pesquisa de campo, 2013.

\section{CONSTRUINDO A QUALIDADE DA FARINHA: O QUE DIZEM OS AGRICULTORES}

Nas comunidades estudadas foram observadas certas distinções na qualidade da farinha produzida, no entanto, observou-se que em ambas essa "construção" segue as mesmas etapas e princípios, as quais norteiam a produção da farinha, iniciando-se com os conhecimentos dos agricultores (e/ou conhecimentos externos apropriados pelos agricultores) relacionados à produção de mandioca, ao fažer farinha, à higiene e às exigências mercadológicas.

\subsection{A ESCOLHA DAS VARIEDADES DE MANDIOCA: O PRIMEIRO ELEMENTO DA CONSTRUÇÃO DA QUALIDADE}

A observação de que a qualidade da farinha começa a ser determinada ainda na roça é destacada por muitas pesquisas (VELTHEM; KATZ, 2012; SILVEIRA, 2009; PINTON; EMPERAIRE, 2004), as quais assinalam principalmente para a escolha da variedade de mandioca que é plantada, a qual segue os conhecimentos e pretensões dos agricultores que as priorizam de acordo com o tempo em que pretendem colhe-las, o tipo de solo na qual a plantará, a coloração preferível ou demandada pelo mercado, a resistência à podridão, dentre outros aspectos.

$\mathrm{Na}$ comunidade Baratinha foi observado que os agricultores prezam pela diversidade, cultivando inúmeras variedades de mandioca, dentre as quais foi possível identificar oito: 'angelim', 'campo', 'mamaluca', 'taxi', 'uruá' e 
'tucumantinga', de coloração branca e, 'santo antônio' e 'jacaré', de coloração amarela, todas consideradas "positivas" pelos agricultores, por apresentar boa produtividade em farinha.

Na comunidade Nova Paz, diferentemente, percebeu-se uma especialização, na qual são selecionadas variedades que combinam produtividade, precocidade, coloração (preferencialmente, amarela) e resistência ao apodrecimento, apresentando a predominância da utilização de duas variedades, a 'taxi' (de coloração branca) e a 'mandioca amarela' (variedade melhorada geneticamente, introduzida na comunidade pela Embrapa).

A predominância de variedades brancas em Baratinha se dá pela priorização dos agricultores pela produção de farinha branca, coloração a qual também é preferência nos mercados de Mocajuba e Areião. Em Nova Paz, tambémse observou que a preferência gustativa dos agricultores é pela 'taxi', que segundo o agricultor $\mathrm{NP} 4^{12}$ produz uma farinha de coloração branca e mais saborosa, que agrada ao paladar do agricultor, embora "não seja bonita para o mercado de Tailândia", que prefere a farinha produzida a partir de mandioca amarela. Segundo ele, o mercado "...prefere comer coisa ruim porque é bonito", afirmação verificada no discurso do agricultor ANP01:

"Aqui nós só mexia com a 'taxi" (...). Agora todo mundo está mudando, que o comércio não está mais muito querendo. O comércio não, o consumidor né? que se o consumidor quiser o comércio não rejeita. O consumidor hoje está querendo mais é coisa de qualidade (coloração amarela)”.

Resultado semelhante foi encontrado por Pinton e Emperaire (2004) ao analisarem a conservação de variedades de mandioca entre povos tradicionais do Acre. As autoras constataram que quanto mais tradicional a forma de produção, maior a quantidade de variedades mantidas, registrando uma média de 48 variedades mantidas por indígenas do Alto Juruá, em contraste com uma média de 2,5 variedades entre os seringueiros, mais integrados ao mercado e em processo de especialização. Segundo Pinton (2001), o manejo da biodiversidade é influenciado pela lógica econômica e necessidade de comercialização, o que costuma gerar uma especialização, na qual os agricultores tendem a privilegiar as variedades que atendam a demanda do mercado.

Além disso, acredita-se que a manutenção desta diversidade de variedades em Baratinha tenha relação com o ano agrícola, uma vez que os agricultores produzem mandioca o ano todo e constatam que cada variedade de mandioca apresenta uma época ideal para colheita, buscando, dessa forma, garantir a produção de farinha de qualidade durante todo o ano. Essa hipótese também foi

12 Sigla adotada para representar os agricultores da comunidade Nova Paz. 
levantada por Rizzi (2011) e confirmada em pesquisa realizada no Acre, onde os agricultores defenderam que a época em que a mandioca fica boa pra colher e a capacidade dela de permanecer sob a terra é um fator importante na escolha das variedades a serem plantadas, o que os leva a plantar aquelas que possibilitam uma colheita rápida (a partir de 8 meses), mas também aquelas que possibilitam colheita mais tardia (até 3 anos).

Em Baratinha, a variedade 'angelim', por exemplo, pode ser colhida com até 2 anos (Agricultor BR0 $5^{13}$ ), enquanto a 'taxi pretinho', deve ser colhida verde, com no máximo 1 ano (Agricultor BR04).O agricultor BR08, acrescenta que se a 'taxi pretinho' não for colhida logo quando fica madura (com 1 ano) "começa a dá uma farinha escura". Fato semelhante é observado para a variedade 'campo', que segundo o agricultor BR01, tem que ser colhida nova, pois quando fica velha, amarga e necessita ser misturada com outras variedades para não alterar o sabor da farinha. A percepção dos agricultores quanto à importância de se colher a mandioca "na hora certa" também foi observada por Silveira (2009), destacando que a colheita realizada com a mandioca verde ou muito madura, dependendo da variedade, pode afetar negativamente a qualidade farinha.

Considerações a respeito do tipo de solo em que é plantada a mandioca também foram elencadas como de influencia na qualidade da farinha em Baratinha. Segundo o agricultor BR06, a mandioca da variedade 'taxi' que é plantada em solo argiloso, tem que ser lavada antes de colocar de molho para produção da farinha, pois "se colocar direto na água fica roxa". Afirmação que também é observada no discurso do agricultor BR02, que menciona: "a farinha da 'taxi' não sai bem branquinha (...) no barro a 'taxi' fica roxa".

Além disso, também foi constatado que o tipo de solo influencia na época da colheita, pois a mandioca plantada na areia chega ao ponto de maturação antes da que é cultivada em solo argiloso: "se for na areia com dez meses começa a tirar, se for no barro tem que deixar completar ano, tem que esperar desenvolver", relata o agricultor BR07. O mesmo foi observado por Rizzi (2011).

Em Nova Paz, os agricultores defendem que a obtenção da farinha de qualidade é definida desde a planta, pois a mandioca que é colhida depende de fatores anteriores para que seja considerada de qualidade, como relata o agricultor NP01:

"Vem primeiro a mandioca de qualidade (...). É como eu digo mesmo, desde a planta, porque se o cara não limpar no tempo certo, ela não vai ser uma mandioca de qualidade, que já vai ter o mato que afeta a raiz dela, um furão vai, fura tudo. Ela tem que ter todo o processo dela desde a planta".

13 Sigla adotada para representar os agricultores de Baratinha 
A percepção de que o local de plantação e a composição do solo interferem na qualidade da farinha também foi apresentado em pesquisa realizada por Velthem e Katz (2012)sobre a percepção de qualidade da farinha de agricultores em comunidades rurais do Acre, no entanto, destaca principalmente a ocorrência de "fiapos" na mandioca quando plantada em solo com ocorrência de certas plantas daninha. O mesmo também foi observado por Silveira (2009) em pesquisa na mesma região, alertando para importância na escolha do solo que se plantará a maniva e nos tratos culturais de controle de pragas e plantas daninhas.

Os tratos culturais como capina e controle de pragas durante a maturação das raízes ajudam a evitar o desenvolvimento de plantas daninhas e aparecimento de pragas que possam afetar o desenvolvimento das raízes ou causar danos como brocas e podridões, que resultarão na perda de rendimento e qualidade da mandioca e, consequentemente, da farinha, que adquiri sabor amargo (SOUZA; FIALHO, 2003).

\subsection{O SABERFAZERNA PRODUCAODA FARINHADEMANDIOCAQUE DETERMINA A QUALIDADE}

Os saberes e o saber fazer dos agricultores são formas de conhecimentos determinantes na produção de uma farinha de boa qualidade, fator observado nas duas comunidades, apesar das diferenças na forma de produção, reiterando a afirmação de Velthem e Katz (2012), que consideram o conhecimento humano como o elemento fundamental no processamento da mandioca. O que se observa é que mesmo com a inserção de novas tecnologias em Nova Paz, os agricultores têm mantido seus saberes, readaptando-os para a nova realidade, fato compreensível uma vez que o conhecimento tradicional é dinâmico (SANTILLI, 2005) e a inserção de artefatos culturais e tecnologias demandam outras formas de fazer, o que influencia no fortalecimento do diálogo de saberes entre as famílias produtoras (SILVA, 2011).

Os agricultores de Baratinha quando questionados sobre o que faz a farinha ser considerada de qualidade, responderam que "tem que saber trabalhar com ela, raspar bem, jogar numa bacia pra amolecer... fazer pouco, com cuidado" (agricultor BR01), ou ainda "tem que secar bem no tipiti, coar numa peneira fina pra não varar crueira e ter paciência no fogo" (agricultor BR02).

Em Nova Paz, da mesma forma, é possível observar cada etapa da produção da farinha na concepção de qualidade, a exemplo do relato do agricultor NP01: 
“...ela (mandioca) não tem que ter podre, se tiver tem que tirar ele tudinho, porque ela não pode ir com nada que vá dá problema na massa. (...) aí vem o processo de torrar ela no tempo... no tempo, porque se você botar ela no retiro hoje, aí amanhã ela já está descascando, ela não deformou, já está dali para o tanque, porque a mandioca com uma hora de tempo de descascado já começa a dá cor, e aquela cor dela vai passar pra massa (...) aí o cara ainda deixa mais uma hora e tanto lá cevadinha, aí ela vai perdendo a qualidade; aí até chegar a torrar... Então quando o cara faz tudo no tempo, ele vai tirar da água ali (tanque de imersão), jogar no triturador, aí já vai imediato para a prensa, que ela não vai pegar aquele vento para deformar, depois que tirar ela não pode passar muito tempo a massa seca ali no (tanque)".

O "raspar bem" mencionado na fala do agricultor BR01 evidencia a necessidade de remover toda a casca da mandioca no momento do descasque, impedindo a passagem desta para a massa, o que resultaria em uma farinha com presença de matéria estranha. O mesmo justifica o entendimento do agricultor BR02 quando se refere ao peneiramento, que é responsável pela separação das partículas de mandioca não reduzidas na trituração, e ainda as cascas e entrecascas que não foram removidas no descascamento. Em Nova Paz, também se percebeu a importância da seleção das raízes, pois os agricultores mencionam ser imprescindível a retirada de raízes pobres e o zelo durante a "rapagem", pois quando tomado o cuidado em retirar as cascas e a "cabeça $a^{14}$ " da mandioca, facilita as etapas de torração e refino (passagem no moinho), diminuindo a quantidade de fiapos e crueira, cuidados necessários para fazer uma farinha de maior qualidade.

Os cuidados quanto ao descascamento da mandioca também foram observados por Silveira (2009) e Velthem e Katz (2012), as quais ressaltam que a presença de "granitos", resultantes de resíduos de cascas pode desqualificar a farinha. Da mesma forma, foram constatadas percepções relacionadas à importância de secar bem a massa (prensagem) e ao peneiramento. Rizzi (2011) constatou ainda, a preocupação quanto a limpeza das raízes e remoção completa da casca da mandioca (externa e interna), a fim de garantir uma mandioca de maior qualidade.

Os agricultores das duas comunidades afirmam que todas as etapas de produção da farinha são importantes para obtenção de uma farinha de qualidade, no entanto, destacam a torração como etapa fundamental para qualidade da farinha. Essa etapa, entretanto, para ser executada exige a presença de um especialista, pois como afirma o agricultor NP03, de Nova Paz, "tem que saberfazer boa, se não for bom torrador, não sai nada que preste”, percepção que é compartilhada pelos agricultores em Baratinha.

$\overline{14}$ Extremidade superior da raiz de mandioca. 
Nas duas comunidades os agricultores consideram que para ser considerado um bom torrador, além de saber identificar as características sensoriais da farinha no momento ideal para encerrar a torração, também é preciso saber controlar a intensidade do fogo durante a torração, o que é imprescindível para obter uma farinha de qualidade, como afirma a agricultora BR01, "tem que fazer duas coisas no mesmo tempo, olhando o fogo e mexendo, se não tomar cuidado com o forno a farinha queima e não torra, embola. (...) tem que controlar a quantidade do fogo, se ficar muito quente ela coze, demora muito a sair".

Os conhecimentos do torrador, repassados de pai para filho no dia-adia da casa de farinha (SILVA, 2011), são imprescindíveis na produção de uma farinha de qualidade, pois segundo Velthem e Katz (2012), o torrador é como um maestro, o qual detém habilidades multidimensionais, como força e habilidade no manejo do rodo, conhecimento sobre o momento preciso para colocar e tirar a lenha para regular a temperatura do forno e a percepção de sabor, cor, odor e textura que atestam que a farinha está no ponto. Já a torração, segundo Lima (1982),é o processo que define a qualidade sensorial da farinha, pois é responsável por conferir cor, sabor e aroma à massa de mandioca, além de reduzir a umidade, o que determina a crocância da farinha.

Além do saberfazer, outra característica requerida para ser um bom torrador é a paciência, pois como afirma o agricultor BR03, "uma farinha de qualidade depende da paciência”. Essa afirmação refere-se à necessidade de limitar a produção diária a poucas sacas de farinha para que obtenha melhor qualidade. Assim, alguns agricultores em Baratinha priorizam produzir menos para obter "farinha boa", como destaca o agricultor BR04, "tem que trabalhar lento, dá dois pacotes de farinha (60 kg) no dia todo, mas sai farinha boa”. Essa percepção é compartilhada com agricultores do Vale do Alto rio Juruá, no Acre, os quais consideram que uma farinha destinada à venda, isto é, uma farinha de qualidade, deve ter produção limitada (VELTHEM; KATZ, 2012).

Em Baratinha, a importância da torração também foi relacionada à prevenção de desenvolvimento de microrganismos na farinha, como afirma o agricultor BR05, "tem que torrar bem, porque quando fica mole ela fica mofenta", reiterando a afirmação de Lima (1982) de que a torração é responsável pela diminuição da umidade da massa que garante a estabilidade microbiológica necessária à conservação da farinha.

Após a torração, alguns agricultores também realizam o peneiramento, outra etapa mencionada como indicativa de uma farinha de qualidade, pois permite a classificação da farinha em grossa, média ou fina, de acordo com as 
exigências do mercado. Essa etapa é realizada nas duas comunidades, com maior frequência em Nova Paz, onde o mercado é mais exigente e prioriza a farinha média, embora as demais também sejam absorvidas em virtude de nichos de clientes específicos que tem preferência por farinha grossa ou fina. Em Baratinha, tanto a farinha fina quanto a grossa é considerada de qualidade, dependendo do mercado ao qual é destinada. Segundo o agricultor BR06 "a grossa é mais vendida no Areião e no Mocajuba é melhor fina”.

\subsection{A IMPORTÂNCIA DA HIGIENE NA QUALIDADE DA FARINHA}

A higiene é outro fator indicado nas duas comunidades como de extrema importância para a obtenção de uma farinha de qualidade, pois como pondera a agricultora BR02, "tem que ter asseio para não sair uma farinha demais feia". Os agricultores defendem que a higienização é uma necessidade constante durante todo o processo de produção da farinha, o que compreende a limpeza das raízes, dos equipamentos e do ambiente de trabalho.

A higiene durante o produção da farinha é essencial para se obter uma farinha de qualidade, pois oportuniza o controle da contaminação microbiológica, principalmente por fungos filamentosos, que são capazes de deteriorar a mandioca durante o processamento (FERNANDES et al., 2013). Corroborando, Velthem e Katz (2012),ressaltam que limpeza do ambiente e dos objetos constitui um aspecto fundamental para a produção de uma boa farinha, pois se estes não forem devidamente higienizados, a massa de mandioca azedará rapidamente, o que altera o sabor da farinha.

A falta de higiene foi constantemente associada às alterações na coloração da massa de mandioca, a qual "fica roxa" - como destaca o agricultor BR04 - além de também alterar o sabor, como pondera o agricultor NP05, "fica amargo e muda a cor se não limpar”. Essas alterações na massa de mandioca em processamento são transferidas para a farinha, afetando diretamente a qualidade, resultando na preocupação dos agricultores com a higiene.

Em Nova Paz, os agricultores afirmam que o zelo é frequente durante todo o processo, pois para que a farinha seja "bonita de cor e boa de gosto", faz-se necessária adoção de práticas higiênico-sanitárias durante todo o processamento, como destaca o agricultor NP01,

“... começa desde lá do tanque, até chegar o final que é a torração. Você pode passar o processo todinho limpando, mas se você não limpar bem o forno, ela vai tirar aquele lixo do forno, vai transmitir... ela não vai dá farinha boa. É por isso que bigiene de farinha você pode colocar desde a hora que termina de descascar. Até para descascar também, 
você não pode jogar num lugar que não esteja limpo, que aquela terra, aquele grude que prega nela ninguém consegue limpar não, só tira a terra, mas o grude não sai, então é por isso que não é permitido jogar assim no chão (...) Tudo ali tem que está limpo mesmo. Tudo onde ela vai passar tem que está limpo".

Em Baratinha, foi observado o mesmo. Segundo os agricultores, a limpeza do retiro é realizada antes de cada farinhada, tomando-se o cuidado para remover todo o resíduo de mandioca da farinhada anterior impregnado nos equipamentos, de forma a não alterar a farinha que será produzida, sendo indispensável o asseio, pois como pondera o agricultor BR01, "tem que ter asseio porque a gente come, a gente vende... a gente trabalha assim, sempre com cuidado, porque se trabalhar bem já tem mais uma saida pra gente... eles vêm em cima da gente logo pra comprar".

Além disso, particularmente em Baratinha, onde se utiliza a casa de farinha tradicional, foi constatada a adoção de estratégias por parte dos agricultores para afastar os animais do local, uma vez que a presença de animais na casa de farinha é considerada um problema. Relatos como o uso de sacas para proteger a mandioca durante a fermentação para que os animais não a contaminem e a utilização de palhas de tucumã ${ }^{15}$ sobre o forno para que os cachorros não o utilizem como dormitório, foram os mais frequentes.

No entanto, estratégias como estas não são consideradas pelos órgãos de vigilância em saúde, sendo os agricultores familiares constantes alvos dos mesmos, pois considerarem que estes não atendem as exigências higiênicosanitárias necessárias para oferecer um alimento seguro, marginalizando os alimentos produzidos pelos agricultores, principalmente os que mantêm métodos tradicionais de produção, considerados rudimentares (CRUZ, 2009).

A pressão para adaptação das casas de farinha aos modelos agroindustriais tem sido crescentes nos últimos anos, com vistas à adoção de boas práticas de fabricação que consiste além dos aspectos higiênico-sanitários a remodelagem das casas de farinha, os quais devem apresentar ambiente fechado, com piso liso de cimento, teto de telha ou zinco (SEBRAE, 2006; VELTHEM, 2007; VELTHEM; KATZ, 2012), como a implantada em Nova Paz ${ }^{16}$ que, foge dos padrões de Baratinha e rompe com a lógica de produção desses agricultores e com a história e o caráter cultural que os modos de produção tradicional

15 Astrocaryumaculeatum é uma palmeira que chega a $15 \mathrm{~m}$ de altura e possui espinhos longos e finos envolvendo o caule e as palhas. Na comunidade acredita-se que a presença dos espinhos ajuda a afastar os animais do forno.

16 Cabe ressaltar que embora tenha sido implantada a agroindústria na comunidade Nova paz, todos os agricultores entrevistados alegaram não ter recebido treinamento em boas práticas de fabricação e manipulação de alimentos e nem de como manipular os novos artefatos introduzidos, tendo os mesmos se adaptado aos poucos, reproduzindo as práticas da tradicional casa de farinha, quando possível. 
apresentam (BLACK, 2005), que embora disponham de "baixo aporte tecnológico e estrutura rústica", têm conseguido atender as exigências da legislação quanto às caraterísticas microbiológicas da farinha (CHISTÉ et al., 2006; CHISTÉ et al., 2007; SANTOS et al., 2012).

\subsection{A QUALIDADE CONSTRUÍDA SEGUNDO AS EXIGÊNCIAS DO MERCADO}

A possível interferência da percepção de qualidade dos comerciantes e atravessadores nas práticas dos agricultores, considerada como hipótese na pesquisa, incentivou a conhecer o que os comerciantes, em Mocajuba e Tailândia e os atravessadores em Areião, realmente dizem ser uma farinha de qualidade, a fim de confirmar, ou não, essa hipótese.

Constatou-se que nas feiras de Mocajuba e Tailândia, a qualidade é associada principalmente às características sensoriais, sendo estas as responsáveis pela escolha da farinha no momento da compra, com destaque para a cor, sabor, torração (crocância) e granulometria, corroborando com Pantoja (2013) em pesquisa realizada com consumidores de farinha do município de Abaetetuba-PA.

Em Mocajuba, preza-se pela coloração branca ou creme, assim como registrado por Pantoja (2013) em Abaetetuba, no entanto, em Tailândia a preferência é por farinha amarela, mas um comerciante alerta que a exigência é por farinha amarela produzida sem adição de corantes artificiais, pois segundo o mesmo, "se botar corante não vende, o pessoal não gosta; farinha com corante aqui é desclassificada". Diferenças como essa também são citadas por Alves e Modesto Júnior (2013), os quais afirmam serem impostas pelos mercados locais que apresentam distintas formas de consumo nas diferentes regiões do Pará.

Essa constatação também ajuda a entender a emergente mudança de priorização da variedade de mandioca cultivada em Nova Paz, onde os agricultores têm se especializado em mandioca amarela a fim de atender ao mercado, reiterando o que defende Sonnino e Marsden (2006) de que a qualidade é construída segundo negociação entre produtores e compradores.

O sabor, a crocância e a granulometria são os fatores seguintes na escala de importância para a escolha da farinha, segundo os comerciantes das duas feiras. A principal exigência quanto ao sabor é que não seja azeda. A crocância, embora não apareça classificada em primeiro lugar na escala de importância, é unânime no discurso dos comerciantes que afirmam ser imprescindível que a farinha seja bem torrada. Já a granulometria, segundo os comerciantes, não deve ser muito fina, o ideal é que não seja "nem grossa, nem fina”, afirma um comerciante 
de Tailândia, embora outro comerciante da referida cidade observe que "o pessoal gosta da farinha grossa pra tomar com açaí".

Em Areião, entretanto, constatou-se que não há uma predefinição de qualidade da farinha, principalmente pelo grande fluxo de comercialização, o que leva os atravessadores a comprarem a farinha à medida que vai chegando. Contudo, um atravessador entrevistado relatou que tem preferência e paga mais quando a farinha é produzida por certos agricultores, os quais são reconhecidos por produzirem farinha de qualidade. Isso reflete a afirmação de Cruz et al. (2008) ao defender que nas relações sociais em canais alternativos de comercialização o nome do produtor se torna uma referência para reconhecer o produto de qualidade. Segundo Prigent-Simonin e Hérault- Fournier (2005), este fato está intimamente ligado à confiança que emerge da relação entre produtor e comprador.

O grupo de farinha considerado de qualidade, nas duas feiras e em Areião foi indicado como sendo a farinha mista (75\% seca e 25\% puba), correspondendo à percepção dos agricultores de Baratinha, no entanto, contrário ao indicado pelos agricultores de Nova Paz, que prezam pela produção de farinha seca. A farinha de qualidade é descrita da seguinte forma pelo atravessador de Areião:

"Tem produtor que coloca a farinha no moedor, eles não colocam na água pra amolecer, eles cortam a mandioca e colocam nesses sacos de palinhas, põe na tábua, deixa um dia, dois... depois tiram, ralam (mandioca recém colhida) e misturam" (Atravessador, Areião, 2013). Grifo nosso.

A preferência por farinha mista ou farinha d'água na região do Baixo Tocantins -PA, também foi constatada por Pantoja (2013) e Linhares e Santos (2014). Esta última ressalta que a escolha pela farinha mista está associada ao sabor da mesma, que ao associar a farinha ralada, considerada doce pelos seus interlocutores, com a farinha puba - mais azeda - resulta em um produto com sabor equilibrado e, portanto, mais aceito.

\subsection{O PREÇO PAGO PELA FARINHA DE QUALIDADE}

Na feira de Mocajuba, 50\% dos comerciantes afirmaram não pagar mais pela farinha de qualidade, pagando apenas o preço de mercado $(\mathrm{R} \$ 60 / 30 \mathrm{~kg}$, em novembro de 2013), no entanto, os demais afirmaram que pagariam até R\$ $100 / 30 \mathrm{~kg}$, no caso de apresentar qualidade diferenciada (farinha mista, branca, classe fina e bem torrada). Na feira de Tailândia foi constatado o pagamento diferencial pela farinha de qualidade, pois um comerciante afirmou comprar a saca de farinha $(60 \mathrm{~kg}$ ) de $\mathrm{R} \$ 150,00$ a $\mathrm{R} \$ 300,00$ (preço em outubro de 2013), dependendo da qualidade da farinha. O maior preço ofertava-se a farinha seca de mandioca amarela, média e bem torrada. 
Entretanto, em Areião, constatou-se que não há distinção de preço entre a farinha considerada de qualidade e a considerada ruim $(\mathrm{R} \$ 50 / 30 \mathrm{~kg}$ em novembro de 2013), fato que acaba por desanimar os agricultores e reflete na qualidade da farinha, como pondera a agricultora BR02: "até desanima a gente, porque chega lá é tudo o mesmo preço (...) muita gente deixou de não se preocupar em fazer uma farinha boa, porque sai demais barato". No entanto, por questões morais, alguns agricultores mantêm a qualidade da produção, como afirma o agricultor BR02, que diz ter vergonha de oferecer uma farinha ruim. O preço inferior oferecido pela farinha em Areião deve-se a presença do atravessador nesse circuito de comercialização.

O baixo valor oferecido pelos compradores, segundo Velthem e Katz (2012), é desproporcional ao investimento humano e aos saberes técnicos, estéticos e simbólicos acumulados pelos agricultores familiares e necessários para a produção de uma farinha de mandioca de qualidade, aspecto também apontado por Silveira (2009) que acrescenta que o preço irrisório oferecido pelos compradores, muitas vezes, não cobre nem os gastos energéticos e financeiros empregados na produção da farinha, contribuindo para o distanciamento entre produtor e seu produto final e, consequentemente, da qualidade da farinha.

Apesar disso, constatou-se que alguns agricultores priorizam a comercialização para compradores conhecidos, mesmo que o preço pago seja mais baixo, como no caso de Baratinha que apresenta dois mercados consumidores e prioriza o que paga menos: Areião ( $\mathrm{R} \$ 50,00 / 30 \mathrm{~kg}$ em novembro de 2013, enquanto em Mocajuba pagava-se R \$70,00/ $30 \mathrm{~kg}$ ). Esta situação foi justificada pela relação de proximidade estabelecida entre produtores e compradores, que até mesmo antecipam o pagamento quando preciso, revelando a formação de uma rede social com base na confiança (WILKINSON, 2002). A consolidação dessas redes sociais também garante a certeza de comercialização do produto, outro fator considerado pelos agricultores de Baratinha na priorização de Areião enquanto principal mercado de escoamento da farinha. $\mathrm{O}$ mesmo foi observado por Bezerra (2014), analisando a venda de farinha de tapioca por agricultores de Santa Izabel-PA, que priorizam a venda a preços mais baratos para atravessadores.

\section{A QUALIDADE DA FARINHA SEGUNDO OS PADRÕES NORMATIVOS}

A análise laboratorial das farinhas permitiu constatar em Baratinha são produzidas majoritariamente farinha de mandioca do grupo d’água (66,6\%, classificadas como mista pelos agricultores), enquanto em Nova Paz há predominância de farinha seca (100\%); quanto à classe, constatou-se a predominância de farinhas grossas em Baratinha $(66,6 \%)$ e média em Nova Paz $(100 \%)$, as quais 
são resultados do processo de peneiramento utilizado em cada comunidade e das exigências do mercado. Os resultados são apresentados na Tabela 1.

Tabela 1 - Classificação e características prováveis de desclassificação das farinhas

\begin{tabular}{c|c|c|c|c|c|c|c|c|c}
\hline COM & AMO & GRU & CLA & ADM & OIP & MES & CIN & UMI & ACI \\
\hline \multirow{2}{*}{ NVP } & A & Seca & Média & Aus. & Aus. & Aus. & $1,25^{\mathrm{a}}$ & $7,86^{\mathrm{a}}$ & $2,80^{\text {cd }}$ \\
& B & Seca & Média & Aus. & Aus. & Aus. & $1,07^{\mathrm{b}}$ & $6,27^{\mathrm{c}}$ & $\mathbf{4 , 1 0 ^ { \text { bc } }}$ \\
& C & Seca & Média & Aus. & Aus. & Pre. & $1,03^{\mathrm{b}}$ & $7,38^{\mathrm{b}}$ & $2,56^{\mathrm{d}}$ \\
\hline \multirow{2}{*}{ BAR } & D & Seca & Grossa & Aus. & Aus. & Aus. & $1,31^{\mathrm{a}}$ & $5,57^{\mathrm{d}}$ & $\mathbf{5 , 2 6 ^ { \mathbf { b } }}$ \\
& E & D'água* & Fina & Aus. & Aus. & Aus. & $1,06^{\mathrm{b}}$ & $4,74^{\mathrm{e}}$ & $\mathbf{6 , 0 8}^{\mathbf{a}}$ \\
& F & D’água* & Grossa & Aus. & Aus. & Aus. & $0,95^{\mathrm{c}}$ & $5,63^{\mathrm{d}}$ & $3,48^{\mathrm{cd}}$ \\
\hline
\end{tabular}

Legenda: $\mathrm{COM}=$ Comunidade de procedência; $\mathrm{NVP}=$ Nova Paz; BAR = Baratinha; $\mathrm{AMO}=$ Amostra; GRU = Grupo; CLA = Classe; $\mathrm{ADM}=$ Aspecto de mofo; OIP =

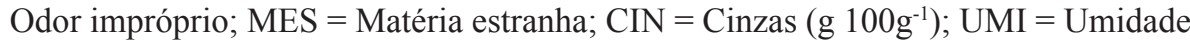
$(\%) ; \mathrm{ACI}=$ Acidez $\left(\mathrm{meq} \mathrm{NaOH} 100 \mathrm{~g}^{-1}\right)$; Aus. = Ausência; Pre. = Presença .

${ }^{\mathrm{a}, \mathrm{b}}$ Letras iguais na mesma coluna não diferem significativamente pelo teste de Tukey $(\mathrm{p} \leq 0,05)$.

*Classificadas pelos agricultores como farinha mista.

A partir dos resultados pode-se observar que as farinhas analisadas não apresentaram aspectos de mofo ou odor impróprio ao produto, o que indica a não proliferação de microrganismos deteriorantes e, portanto, estado de conservação apropriado, o que se justifica pelo baixo índice umidade apresentado por todas as farinhas, os quais se encontram dentro do indicado pela legislação nesse quesito (máximo de 13\%). No entanto, quando analisada a existência de matéria estranha, verificou-se a presença de partes de insetos em uma amostra coletada em Nova Paz, sendo assim desclassificada por ser considerada imprópria ao consumo, de acordo com Brasil (2011).

Em relação à acidez, três amostras se encontraram acima do máximo estabelecido pela legislação (BRASIL, 2011).Dessas, duas foram produzidas em Baratinha e uma em Nova Paz. A elevada acidez das farinhas pode ser justificada pela falta de controle no processo de fermentação, pois como alerta Chistéet al. (2006), nas casas de farinhas do interior do Pará, a massa de mandioca triturada fica exposta de um dia para o outro à temperatura ambiente $\left(25^{\circ} \mathrm{C}\right.$ a $\left.35^{\circ} \mathrm{C}\right)$, colaborando para elevação da acidez. Quanto ao teor de cinzas, todas as amostras se encontraram em acordo com o estabelecido pela legislação (BRASIL, 2011).

O teste de Tukey revelou diferença significativa em todos os parâmetros avaliados (cinzas, umidade e acidez), com destaque para umidade e acidez, onde houve diferença significativa tanto entre as farinhas produzidas em comunidades diferentes, quanto entre as produzidas na mesma comunidade, revelando a 
heterogeneidade do saber faz̧er na fabricação do produto, uma vez que esses fatores, segundo Chistéet al. (2006), estão relacionados ao processo de fabricação.

\section{CONCLUSÃO}

A pesquisa se propôs a investigar a hipótese de que a qualidade da farinha é construída socialmente de acordo com percepções diversas dos indivíduos envolvidos na cadeia de produção e comercialização da farinha (agricultores e comerciante-compradores) e, que estas percepções orientam as práticas adotadas por cada um dos agricultores no fazer farinha, a partir de estudo exploratório em duas comunidades rurais diferenciadas no Território do Baixo Tocantins, Nova Paz e Baratinha.

Os resultados possibilitaram constatar que a qualidade da farinha é construída durante toda a cadeia produtiva, iniciando ainda na roça, com destaque para a variedade de mandioca cultivada e a colheita da raiz no "tempo certo"; as práticas na produção da farinha, com destaque para o saber fažer, principalmente durante a torração; higiene durante todo beneficiamento; e as relações sociais entre agricultores e compradores, apreendidas enquanto exigências mercadológicas.

Na comunidade Baratinha, particularmente, observou-se que a concepção de qualidade ainda está atrelada aos conhecimentos tradicionais que são reproduzidos e/ou reconstruídos em função da qualidade da farinha, apresentando uma grande diversidade de variedades de mandioca e a utilização do sistema tradicional de produção, enquanto em Nova Paz, observou-se a especialização do sistema de produção com diminuição da diversidade de variedades de mandioca, inserção de novas tecnologias no fazer farinha e forte racionalidade comercial.

A relação com o mercado e a influência deste nas práticas adotadas pelos agricultores constatou-se marcante nas duas comunidades, confirmando a hipótese de que os comerciantes/consumidores exercem influência na qualidade da farinha produzida, através das exigências feitas ao produtor. Todavia, é importante frisar que embora ocorra essa interferência da relação agricultorcomerciante nas práticas adotadas para produção da farinha, não significa dizer, necessariamente, que interfere na concepção de qualidade dos agricultores, as quais muitas vezes foram distintas. Existe assim, um processo diferenciado de produção de farinha pelos agricultores, um para o consumo local, outro dirigido para mercado. O preço orienta também as escolhas.

A utilização do sistema agroindustrial pelos agricultores de Nova Paz possibilitou uma maior padronização da granulometria da farinha, em virtude da tecnologia disponível. No entanto, a agroindustrialização da produção e o acesso 
à assistência técnica por esses mesmos agricultores, não garante, por si só, a qualidade físico-química e higiênico-sanitária da farinha produzida, uma vez que apresentou farinhas com parâmetros em desacordo com os padrões legislativos e a única farinha desclassificada foi coletada nessa comunidade. O que se percebeu foi que mesmo em Nova Paz os agricultores desconhecem ou desconsideram as legislações referentes à qualidade da farinha, operando de acordo com seus saberes, os interesses próprios e da rede social na qual estão inseridos.

Assim, constata-se que a forma tradicional de produção da farinha, embora apresente limitantes, também é capaz de garantir farinha de qualidade, legitimando o saber fazer tradicional e evidenciando a importância do conhecimento dos agricultores, o qual lhes permite manter a qualidade e a real complexidade desta noção bem apreendida como construção social.

Ressalta-se, dessa forma, a necessidade do fortalecimento das pesquisas que ultrapassem a noção operacional de qualidade utilizada pelas agências reguladoras e contribuam para o reconhecimento dos agricultores enquanto atores sociais dotados de saberes e competências necessárias para a produção de alimentos de qualidade e o incentivo da criação de legislações adequadas à realidade desses produtores, assim como de políticas públicas orientadas para o incentivo da produção tradicional de alimentos.

\section{REFERENCIAS}

ALVES, R. N. B.; MODESTO JÚNIOR, M. S. Mercado exige características distintas de produção de farinha de tapioca em duas regiões no estado do Pará. Portal EcoDebate, n. 1.942, 2013. Disponível em: http://www.ecodebate.com.br/2013/10/17/mercado-exigecaracteristicas-distintas-de-producao-de-farinha-de-tapioca-em-duas-regioes-no-estado-dopara-por-raimundo-nonato-brabo-alves-e-moises-de-souza-modesto-junior/.Acessoem: 17 set. 2015.

AOAC. Official methods of analysis of the Association of Official Analytical Chemists.16a Ed., v.2. Washington: Edited Ig W. Horwitz, 1997.

BEAUD, S.; WEBER, F. Guia para a pesquisa de campo: produzir e analisar dados etnográficos. Petrópolis: Editora Vozes, 2007.

BEZERRA, F. A. P. Declínio da produção de mandioca: os impactos econômicos no município de Santa Izabel, Estado do Pará. Agroecossistemas, Marabá, v. 6, n. 1, p. 17-41, 2014.

BRASIL. Ministério da Agricultura, Pecuária e Abastecimento. Instrução Normativa $\mathbf{n}^{\mathbf{0}} \mathbf{5 2}$, de 7 de novembro de 2011. Estabelece o Regulamento Técnico da Farinha de Mandioca. Diário Oficial da União. Brasília, 2011.

CHISTÉ, R. C.; COHEN, K. O.; MATHIAS, E. A.; RAMOA JÚNIOR, A. G. A. Qualidade da farinha de mandioca do grupo seca. Ciência e Tecnologia de Alimentos, Campinas, v. 26, n. 4, p. 861-864, 2006. 
Estudo das propriedades físico-químicas e microbiológicas no processamento da farinha de mandioca do grupo d'água. Ciência e Tecnologia de Alimentos, Campinas, v.27, n.2, p.265-269, 2007.

COSTA, A. C. S.; PONTES, F. H. G.; SOUSA, F. F.; CHAVES, G. P.; SANCHES, K. M. S.Diagnóstico Rural Participativo da comunidade Nova Paz, Tailândia - PA. Belém: Universidade Federal do Pará, 2013.

CRUZ, F. T.; MENASCHE, R.; KRONE, E. E.; WAGNER,S. A. Queijo artesanal serrano dos campos de cima da serra: o saber-fazer tradicional desafiando a qualidade. Anais... IV CONGRESSO INTERNACIONAL DE LA RED SIAL. Mar de la Plata, 27 a 31 de outubro de 2008.

Qualidade dos alimentos e escalas de produção: em defesa de critérios e normas para legitimação dos produtos artesanais/tradicionais. In: $47^{\circ} \mathrm{CONGRESSO}$ DA SOCIEDADEBRASILEIRA DEECONOMIA,ADMINISTRAÇÃO ESOCIOLOGIA RURAL. Anais... Porto Alegre, 26 a 30 de julho de 2009.

ESTIVAL, K. G. S. Construção social do mercado de qualidade do cacau no Brasil. 312p. 2013. Tese (Doutorado em Ciências Sociais em Desenvolvimento, Agricultura e Sociedade) - Instituto de Ciências Humanas e Sociais,Universidade Federal Rural do Rio de Janeiro, Seropédica, 2013.

FERNANDES, H. R.; OLIVEIRA, D. C. R.; SOUZA, G. S.; LOPES, A. S. Parâmetros de qualidade física e físico-química da farinha de mandioca (Manihot esculenta Crantz) durante processamento. Scientia Plena, Sergipe, v.9, n.11, 2013.

LIMA, U. A. Manual técnico de beneficiamento e industrialização da mandioca. São Paulo: Secretária de Ciência e Tecnologia, 1982.

LINHARES, A. S.; NUNES, K. L.; BARROS, L. C.; BASTOS, R. F. Diagnóstico da comunidade Baratinha do município de Mocajuba no Baixo Tocantins/Pará. Belém: Universidade Federal do Pará, 2013.

LINHARES, A. S.; SANTOS, C. V. “A casa de farinha é a minha morada”: transformações e permanências na produção de farinha em uma comunidade rural na região do Baixo Tocantins-PA. Agricultura Familiar, n.10, p53-66, Belém, 2014.

NUNES, K. L.; SIMÕES, A. V. Ensaio acerca da trajetória dos sistemas técnicos de produção de farinha de mandioca na comunidade Baratinha, Mocajuba-PA, Território do Baixo Tocantins. In: X CONGRESSO DA SOCIEDADE BRASILEIRA DE SISTEMAS DE PRODUÇÃO. Anais... Foz do Iguaçu: SBSP, 14 a 17 de maio de 2014.

PANTOJA, T. C. Qualidade e preferência da farinha de mandioca na comunidade Nossa Senhora da Paz em Abaetetuba, Pará: cor, sabor e aparência dos grãos. 31p. Monografia (Especialização em Extensão Rural, Sistemas Agrários e Ações de Desenvolvimento), Núcleo de Ciências Agrárias e Desenvolvimento Rural, Universidade Federal do Pará, Belém, 2013.

PINTON, F. (éd.). Marché em hausse, savoirs em baisse? Diversité variétale du manioc, gestions locales et marché de la farine en Amazonie (Brésil, Guyana). Rapport final pour le Programme Environnement, Viet et Sociétés du CNRS. Comité Systèmes écologogiques et Actions de I'homme, 2001. 
PINTON, F.; EMPERAIRE, L. Agrobiodiversidade e agricultura tradicional na Amazônia: que perspectiva? In: SAYAGO, D.; TOURRAND, J. F.; BURSZTYN, M. (Orgs.). Amazônia: cenas e cenários. Brasília: Universidade de Brasília, 2004. p.73-100.

PRIGENT-SIMONIN, A. H.; HÉRAULT-FOURNIER, C. The role of trust in the perception of the quality of local food products: with particular reference to direct relationships between producer and consumer. Anthropology of Food, n. 4, 2005. URL: http://aof.revues.org/204

RIZZI, R. Mandioca: processos biológicos e socioculturais associados no Alto Juruá, Acre. 177p. 2011. Dissertação (Mestrado em Antropologia Social) - Instituto de Filosofia e Ciências Humanas, Universidade Estadual de Campinas, Campinas, 2011.

SANTOS, T. T.; SOUZA, E. X. N.; SILVA, L. C.; CAZETTA, M. L. Avaliação microbiológica e físico-química da farinha de mandioca comercializada no mercado municipal de Cruz das Almas - BA. Magistra, Cruz das Almas, v.24, n.1, p.34-41, 2012.

SEBRAE, Serviço Brasil de apoio às Micro e Pequenas Empresas. Casas de farinha: manual de boas práticas. Alagoas: SEBRAE, 2006.

SILVA, C. S. S.Casas de farinha: espaço de (con) vivências, saberes e práticas educativas. 179p. 2011. Dissertação (Mestrado em Educação), Centro de Ciências Sociais e Educação, Universidade do Estado do Pará,Belém, 2011.

SILVEIRA, J. S. A multidimensionalidade da valorização de produtos locais: implicações para políticas públicas, mercado, território e sustentabilidade na Amazônia. p. 391. 2009. Tese (Doutorado em Desenvolvimento Sustentável), Universidade de Brasília, Brasília, 2009.

SONNINO, R.; MARSDEN, T. Beyond the divide: rethinking relationships between alternative and conventional food networks in Europe. Journal of Economic Geography, v.6, n.2, p.181-199, 2006.URL: http://joeg.oxfordjournals.org/content/6/2/181.short

SOUZA, L. S.; FIALHO, J. F. Sistema de produção de mandioca para a região do cerrado. Cruz das Almas: Embrapa Mandioca e Fruticultura, 2003. 61p.

TRICHES, R. M. A ressignificação da qualidade dos alimentos na construção de mercados locais: o caso da alimentação escolar. In $5^{\circ}$ ENCONTRO DA REDE DE ESTUDOS RURAIS. Anais.... Belém, 3 a 6 de junho de 2012.

VELTHEM, L. H. Farinha, casas de farinha e objetos familiares em Cruzeiro do Sul (Acre). Revista de Antropologia, São Paulo, v.50, n.2, p.605-631, 2007.

VELTHEM, L. H.; KATZ, E. A 'farinha especial': fabricação e percepção de um produto da agricultura familiar no Vale do rio Juruá, Acre. Boletim do Museu Paraense Emílio Goeldi. Ciências Humanas, Belém, v. 7, n. 2, p. 435-456, 2012.

VERDEJO, M. E. Diagnóstico Rural Participativo: Um guia prático. Brasília: Secretaria da Agricultura Familiar - SAF, 2006. 61 p.

WILKINSON, J. Sociologia econômica, a teoria das convenções e o funcionamento dos mercados: inputs para analisar os micro e pequenos empreendimentos agroindustriais no Brasil. Ensaios FEE, Porto Alegre, v.23, n.2, p.805-824, 2002.

Texto submetido à Revista em 19.09.2014

Aceito para publicação em 13.07.2015

Novos Cadernos NAEA • v. 18 n. $3 \cdot$ p. 199-222 • set-dez. 2015 